\title{
Investigation of the Electric Field of Metallic Fence under a High Voltage Transmission Line
}

\author{
Juozapas Arvydas Virbalis ${ }^{1}$, Robertas Lukocius, Povilas Marciulionis ${ }^{1}$, Gabija Nedzinskaite ${ }^{1}$, \\ Paulius Vaskys ${ }^{1}$ \\ ${ }^{1}$ Department of Electric Power Systems, Kaunas University of Technology, \\ Studentu St. 48-230, LT-51367 Kaunas, Lithuania \\ gabija.nedzinskaite@ktu.lt
}

\begin{abstract}
There could be areas near a high voltage power transmission lines where electric field strength can exceed maximum permissible values and could be harmful to workers. Territory of the open switch-gear with a metallic fence can be dangerous especially because the power line wires there are at a relatively low height. Therefore, it is important to know surely what the values of electric field strength are near a fence. The expressions for calculation of electric field strength at any observation point near the three-phase line with near the line set metallic fence dependently on the geometrical parameters of line and fence and the coordinates of observation point are presented in the paper. 2D approach is applied to implement the task. Values of electric field strength, obtained applying the analytical method, were compared with the numerically calculated ones. The comparison showed that difference between results obtained by analytical calculations and results obtained by numerical modelling is not greater than $10 \%$. The results show that there is some area near the fence in which the electric field strength exceeds permissible values.
\end{abstract}

Index Terms-Effective value; electric field strength; high voltage power line; fence; open switch-gear.

\section{INTRODUCTION}

According to the Directive 2013/35/ES of the European Parliament and of the Council [1] workers can't work in the workplaces where the effective value (rms) of $50 \mathrm{~Hz}$ alternating electric field exceeds $10 \mathrm{kV} / \mathrm{m}$ The admissible values of electric field depend on impact time and the field with value $-10 \mathrm{kV} / \mathrm{m}$ can act workers not more than $10 \mathrm{~min}$ according to Lithuanian standards [2].

The results of electric field distribution investigation in $330 \mathrm{kV}$ open switch-gear are presented in [3]. There are some areas, in which electric field strength values exceed the limit established by Directive in $1,8 \mathrm{~m}$ height because the height of high voltage wires is reduced to $6,5 \mathrm{~m}$ in open switch-gear.

The greatest values of electric field strength are actually under a high voltage lines. But the intense electric field may be not only in neighbourhood of high voltage wires. The dangerous values of electric field may be near the grounded metallic installations. Therefore, the metallic fence which surrounds the open gear may be dangerous, too. Therefore, it is important to know the electric field distribution near fence also.

Manuscript received 15 February, 2016; accepted 29 October, 2016.
Some authors have provided the calculation methods and values of the electric and magnetic fields, corona losses [4][10]. It is clear from the results that electric field could have greater values at the high voltage power lines. There is a lack of analytical methods to calculate effective values of three phase line electric field without using expensive computer programs and big computer memory capacities. Calculation of the real electric or magnetic field values is difficult solution because the results greatly depend on parameters of the soil. Some of the authors propose soil models and describes dependences of their parameters according to humidity, soil structure, ground surface [11] [19]. We use the simpler model with ideal ground potential in this paper.

There can be the zones near three phase high voltage lines in which electric field strength exceed maximum permissible values and can disrupt or endanger the health of workers who operate and maintain electrical equipment [15]-[16]. Territory of the open switch-gear is dangerous especially because the height of line wires there is low and electric field gains the greater values. Consequently, it is extremely important to know the strength of the electric field at height of up to $2 \mathrm{~m}$ in the switch-gear territory.

We investigate the electric field near the metallic fence situated in neighbourhood of the high voltage line analytically and by modelling in this paper. Electric charges induced by high voltage wires are concentrated in upper part of fence which is the closest to wires. So we can present the fence as grounded wire situated in the upper part of the fence.

We used image method for field distribution investigation as in [3]. The dimensions of open switch-gear are small in comparison with $50 \mathrm{~Hz}$ electric field wave length. We applied an assumption that electric field distributes without inertia in all investigation area.

\section{Calculation of the Electric Field Near Fence PARALLEL TO THE LINE WIRES}

We do not evaluate sag of the wires. So in any perpendicular to line wires plane the section of wires and fence will be the same (Fig. 1). The electric field of investigated system is two-dimensional analogically to the case analysed in [3].

In Fig. 1 there are noted: $\tau_{\mathrm{A}}, \tau_{\mathrm{B}}$ and $\tau_{\mathrm{C}}-$ linear charge 
densities of the phase wires $\mathrm{A}, \mathrm{B}$ and $\mathrm{C}$, accordingly, in plane perpendicular to the wires and the fence, $\tau_{\mathrm{T}}-$ the induced linear charge density in the grounded fence in same plane, $\tau_{\mathrm{A}}{ }^{*}, \tau_{\mathrm{B}}{ }^{*} \tau_{\mathrm{C}}{ }^{*}$ and $\tau_{\mathrm{T}}{ }^{*}$ - images of the appropriate linear charge densities in respect to the ground plane, $h$ - the distance between top of the fence and the ground, $H$ - the distance between the line wires at the ground, $a-$ the distance between neighbouring wires of the line, $c$ - the distance between the upper part of fence and the closest line wire in the horizontal plane, $b$ - the distance at the upper fence part to the observation point $\mathrm{M}$. We suppose that the upper part of fence is cylinder with the radius $r_{\mathrm{T}}$. The radius of line wires is $r_{\mathrm{F}}$. The linear charge densities $\tau_{\mathrm{A}}, \tau_{\mathrm{B}}, \tau_{\mathrm{C}}$ and $\tau_{\mathrm{T}}$ are situated on the axes of the line wires or fence, accordingly. Agreeably to the images method $\tau_{\mathrm{A}}{ }^{*}=-\tau_{\mathrm{A}}, \tau_{\mathrm{B}}{ }^{*}=$ $-\tau_{\mathrm{B}}, \tau_{\mathrm{C}}{ }^{*}=-\tau_{\mathrm{C}}$ and $\tau_{\mathrm{T}}{ }^{*}=-\tau_{\mathrm{T}}$.

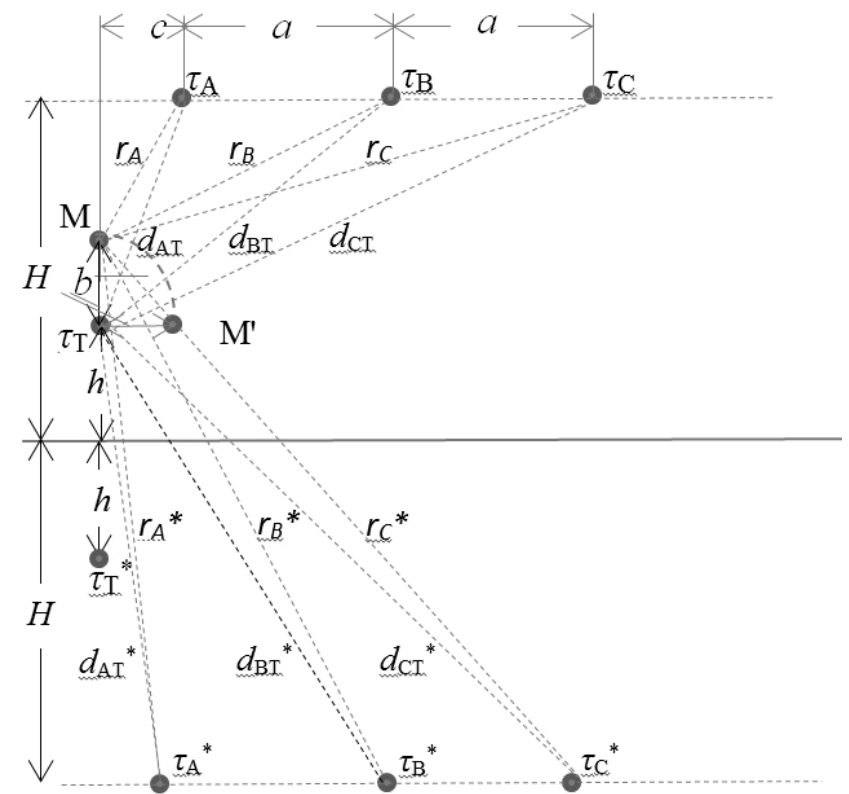

Fig. 1. The situation of linear charges densities in the plane perpendicular to the line wires.

We can relate the potentials and charge densities of the investigated points at any moment of the time by Maxwell equations system [4]. This system could be written in matrix form as

$$
[u]=\left[\alpha_{\mathrm{P}}\right]\left[\tau_{\mathrm{P}}\right],
$$

where $[\mathrm{u}]^{\mathrm{T}}=\left[\mathrm{u}_{\mathrm{A}}, \mathrm{u}_{\mathrm{B}}, \mathrm{u}_{\mathrm{C}}, 0\right]$ is the matrix of potential coefficients, $\left[\tau_{\mathrm{P}}\right]^{\mathrm{T}}=\left[\tau_{\mathrm{A}}, \tau_{\mathrm{B}}, \tau_{\mathrm{C}}, \tau_{\mathrm{T}}\right]$ is the matrix of linear charges. The matrix elements $\left[\alpha_{P}\right]$ can be expressed, as follows (2)-(9) [3]:

$$
\begin{gathered}
\alpha_{11 \mathrm{P}}=\alpha_{22 \mathrm{P}}=\alpha_{33 \mathrm{P}}=\frac{1}{K_{0}} \ln \frac{2 H}{r_{F}}, \\
\alpha_{44 \mathrm{P}}=\frac{1}{K_{0}} \ln \frac{2 h}{r_{T}}, \\
\alpha_{12 \mathrm{P}}=\alpha_{21 \mathrm{P}}=\alpha_{23 \mathrm{P}}=\alpha_{32 \mathrm{P}}= \\
=\frac{1}{K_{0}} \ln \frac{d^{*}}{d_{g}}=\frac{1}{K_{0}} \ln \frac{\sqrt{(2 H)^{2}+a^{2}}}{a},
\end{gathered}
$$

$$
\begin{gathered}
\alpha_{13 \mathrm{P}}=\alpha_{31 \mathrm{P}}=\frac{1}{K_{0}} \ln \frac{d_{\mathrm{AC}}^{*}}{d_{\mathrm{AC}}}=\frac{1}{K_{0}} \ln \frac{\sqrt{(2 H)^{2}+4 a^{2}}}{2 a} \\
\alpha_{14 \mathrm{P}}=\alpha_{41 \mathrm{P}}=\frac{1}{K_{0}} \ln \frac{d_{\mathrm{AT}}^{*}}{d_{\mathrm{AT}}}=\frac{1}{K_{0}} \ln \frac{\sqrt{(H+h)^{2}+c^{2}}}{\sqrt{(H-h)^{2}+c^{2}}}, \\
\alpha_{24 \mathrm{P}}=\alpha_{42 \mathrm{P}}=\frac{1}{K_{0}} \ln \frac{d_{\mathrm{BT}}^{*}}{d_{\mathrm{BT}}}=\frac{1}{K_{0}} \ln \frac{\sqrt{(H+h)^{2}+(a+c)^{2}}}{\sqrt{(H-h)^{2}+(a+c)^{2}}} \\
\alpha_{24 \mathrm{P}}=\alpha_{42 \mathrm{P}}=\frac{1}{K_{0}} \ln \frac{d_{\mathrm{BT}}^{*}}{d_{\mathrm{BT}}}= \\
=\frac{1}{K_{0}} \ln \frac{\sqrt{(H+h)^{2}+(2 a+c)^{2}}}{\sqrt{(H-h)^{2}+(2 a+c)^{2}}} \\
{\left[K_{0}=2 \pi \varepsilon_{\mathrm{a}}\right]}
\end{gathered}
$$

where $\varepsilon_{\mathrm{a}}$ is absolute dielectric constant of the environment, $d_{\mathrm{g}}$ - the distance between the charge densities of neighbouring phases, $d_{\mathrm{g}}{ }^{*}-$ the distance between the charge density of some phase and the charge density of neighbouring phase image, $d_{\mathrm{AC}}-$ the distance between the charge densities of phases $\mathrm{A}$ and $\mathrm{C}, d_{\mathrm{AC}}{ }^{*}$ - the distance between the linear charge density of phase $\mathrm{A}$ and the image of linear charge density of phase $\mathrm{C}$ or between the image of linear charge density of phase $\mathrm{A}$ and the linear charge density of phase $\mathrm{C}, d_{\mathrm{AT}}, d_{\mathrm{BT}}$ ir $d_{\mathrm{CT}}-$ the distances between the linear charge density of fence and the charge densities, accordingly, of A, B and $\mathrm{C}$ phase lines, $d_{\mathrm{AT}}{ }^{*}, d_{\mathrm{BT}}{ }^{*}$ and $d_{\mathrm{CT}}{ }^{*}-$ the distances between the charge density of fence and the images of charge density, accordingly, of A, B and C phase lines or, vice versa, the distances between the image of charge density of fence and the charge densities, accordingly, of A, B and C phase lines. All these distances are the straight lines and can be calculate as hypotenuses of triangles (Fig. 1).

After calculation elements of the matrix $\left[\alpha_{\mathrm{P}}\right]$, we must calculate the inverse matrix as

$$
\left[\beta_{P}\right]=\left[\alpha_{P}^{-1}\right]
$$

Then we can calculate of linear charge densities of the line wires and the fence as

$$
\left[\tau_{\mathrm{P}}\right]=\left[\beta_{\mathrm{P}}\right][u]
$$

All of these charge densities create the electric field in observation point $\mathrm{M}$. The electric field strength of any charge density can be expressed in this way as

$$
E_{M i}(t)=\tau_{i}(t) / K_{0} r_{M i},
$$

where $\tau_{i}$ - linear charge density of $i$-th point, $r_{\mathrm{M} i}-$ the distance from this point to the observation point $\mathrm{M}, i-$ indexes $\mathrm{A}, \mathrm{B}, \mathrm{C}, \mathrm{T}$.

To find the effective value of electric field strength we calculated total moment value of electric field $E(t)=\sqrt{E_{x}^{2}(t)+E_{y}^{2}(t)}$ and found effective value 
$E=\sqrt{\frac{1}{T} \int_{0}^{T} E(t)^{2} d t}$ in the observation point. These procedures are discussed in [3].

\section{ELECTRIC FIELD NEAR THE SidES OF THE FENCE PERPENDICULAR TO THE LINE WIRES}

The view of the real open switch-gear is presented in the Fig. 2. We suppose that the line wires $\mathrm{A}, \mathrm{B}$ and $\mathrm{C}$ are infinite in respect to the fence. We set the plane $\mathrm{P}$ perpendicular to the line wires and coincident with the fence side axis. As shown in Fig. 3 the field strength will have only vertical component because the horizontal components created by charge densities situated in the same distance at the plane $\mathrm{P}$ in right and left sides will compensate each other. The electric field strength vector has two-dimensions in the plane $\mathrm{P}$

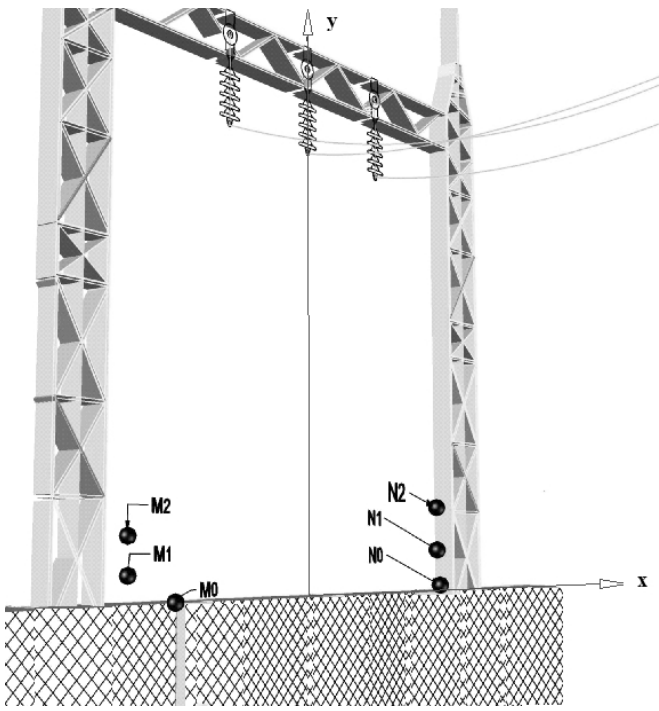

Fig. 2. Fence situated near the high voltage power line.

Electric field will be created by linear charge densities of line wires and fence in the observation point as in the case of parallel fence side. Charge density of the fence $\tau_{\mathrm{T}}$ depends on coordinate $x$ differently as in case of parallel fence (Fig. 3). But it is sufficient to investigate the system of 4 charge densities and its images in this case, too.

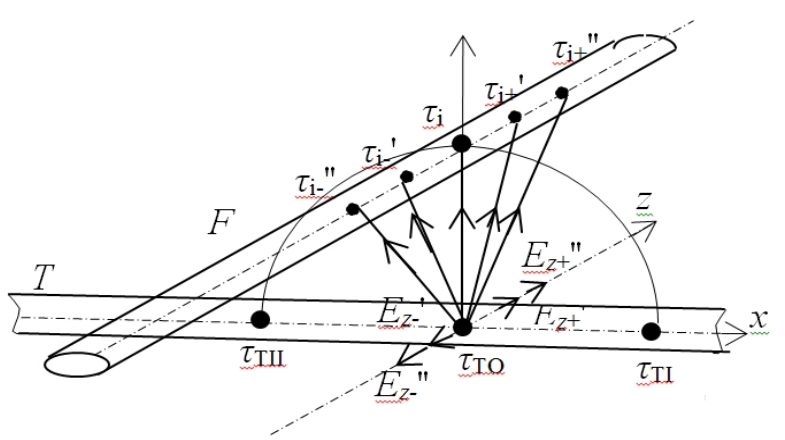

Fig. 3. Electric field between the phase line and perpendicular to it fence side.

The charge densities can be calculated from (1)-(11). Distances $d_{\mathrm{AT}}, d_{\mathrm{AT}}{ }^{*}, d_{\mathrm{BT}}, d_{\mathrm{BT}}{ }^{*}, d_{\mathrm{CT}}$ and $d_{\mathrm{CT}}{ }^{*}$ are not straight lines in common case. These distances are the lengths of electric field lines between suitable charge densities in the plane $\mathrm{P}$.
The line wires and the fence surface are equipotential. Therefore, electric field lines must be perpendicular to both surfaces. Distance between linear charge densities of line wire $\mathrm{F}$ and fence $\mathrm{T}$ will be straight line only in the case when the fence point with charge density $\tau_{\mathrm{TO}}$ is just under the line wire (the axis $y$ in Fig. 3). Distances between the charge densities $\tau_{\mathrm{i}}$ and $\tau_{\mathrm{TI}}$ as between the charge densities $\tau_{\mathrm{i}}$ and $\tau_{\mathrm{TII}}$ are not straight lines. Three situations of observation points are showed in Fig. 4. The observation point $\mathrm{S}$ presents the common case.

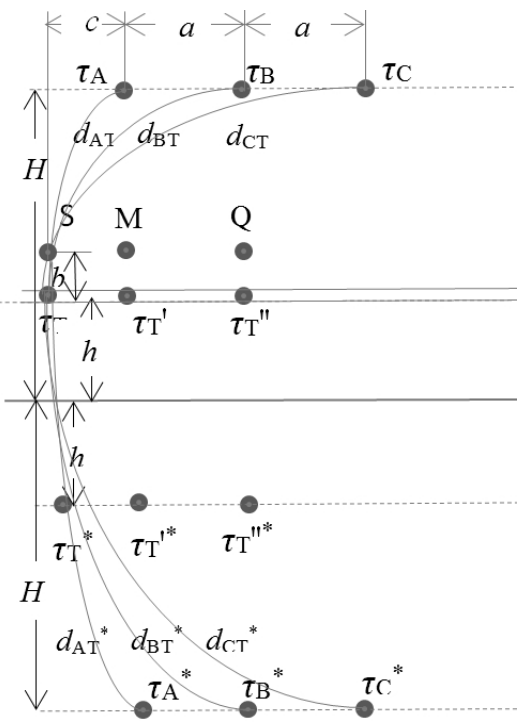

Fig. 4. The situation of charge densities in investigative electric field.

It is commonly known for electromagnetic field theory that the two charge densities conjunctive electric field lines are the circle arcs in common case. Therefore, the distances $d_{\mathrm{AT}}, d_{\mathrm{AT}}{ }^{*}, d_{\mathrm{BT}}, d_{\mathrm{BT}}{ }^{*}, d_{\mathrm{CT}}$ and $d_{\mathrm{CT}}{ }^{*}$ we must calculate as circle arcs.

Calculation of distances $d_{i T}(I=\mathrm{A}, \mathrm{B}, \mathrm{C})$ by Fig. 5 the $R$ is radius of $\operatorname{arc} d_{\mathrm{iT}}(\mathrm{x}), \alpha$ is angular dimension of this arc. The distance between the points $\tau_{i}(I=\mathrm{A}, \mathrm{B}, \mathrm{C})$ and $\tau_{\mathrm{T}}$ in the vertical direction is $h$, the distance in the horizontal direction is $g$.

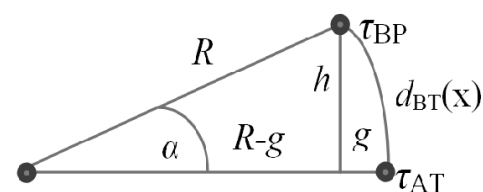

Fig. 5. Relationship among the arc length $d_{\mathrm{iT}}$ and distances $g$ and $h$.

The arc length $d_{i \mathrm{~T}}$ is written as

$$
d_{i T}=R a
$$

We express the distance $R$ and $\alpha$ via $g$ and $h$ from Fig. 5

$$
R=\frac{g^{2}+h^{2}}{2 g}
$$

If inequality $h \geq g$ is true then angle $\alpha$ will be as follows

$$
\alpha=\arcsin \frac{h}{R}=\arcsin \frac{2 g h}{g^{2}+h^{2}} .
$$


In other case when $g>h$ then angle $\alpha$ is

$$
\alpha=\pi-\arcsin \frac{h}{R}=\pi-\arcsin \frac{2 g h}{g^{2}+h^{2}} .
$$

Expressions (13)-(16) could be used for the distances $d_{i \mathrm{~T}}{ }^{*}$ calculation but in this case $h=H+h$.

Charge densities could be expressed in this way because of the fence potential is zero. From (11):

$$
\begin{aligned}
& \tau_{A}=\beta_{11} u_{A}+\beta_{12} u_{B}+\beta_{13} u_{C}, \\
& \tau_{B}=\beta_{21} u_{A}+\beta_{22} u_{B}+\beta_{23} u_{C}, \\
& \tau_{C}=\beta_{31} u_{A}+\beta_{32} u_{B}+\beta_{33} u_{C}, \\
& \tau_{T}=\beta_{41} u_{A}+\beta_{42} u_{B}+\beta_{43} u_{C} .
\end{aligned}
$$

The electric field strength was expressed in two important points: under the outside line wire $A$ and under middle line wire B. Situation of electric field strength in the point $M$ under phase A wire calculation is shown in Fig. 4. Distance $b$ from fence to observation point is in vertical direction (along axis $y$ in Fig. 3 or Fig. 4). Distance between charge density in the fence $\tau_{\mathrm{TA}}$ and the phase $\mathrm{A} \tau_{\mathrm{A}}$ is straight line. Inequalities $b<<d_{\mathrm{BT}}, b<<d_{\mathrm{BT}}{ }^{*}, b<<d_{\mathrm{CT}}, b<<d_{\mathrm{BT}}{ }^{*}$ are usually true. It could be supposed that $b$ is part of $\operatorname{arcs} d_{i \mathrm{~T}}$ in this case. The electric field strength $E_{\mathrm{M}}$ in the point $\mathrm{M}$ can be expressed as follows

$$
\begin{aligned}
E_{\mathrm{M}}= & \frac{1}{K_{0}} \times\left[\frac{\tau_{\mathrm{AT}}}{b}-\frac{\tau_{\mathrm{AT}}}{2 h+b}+\frac{\tau_{\mathrm{A}}}{(H-h)-b}+\frac{\tau_{\mathrm{A}}}{H+h+b}+\right. \\
& \left.+\frac{\tau_{\mathrm{B}}}{d_{\mathrm{BT}}-b}+\frac{\tau_{\mathrm{B}}}{d_{\mathrm{BT}}^{*}+b}+\frac{\tau_{\mathrm{C}}}{d_{\mathrm{CT}}-b}+\frac{\tau_{\mathrm{C}}}{d_{\mathrm{CT}}^{*}+b}\right] .
\end{aligned}
$$

Direction of the electric field is perpendicular to the surface of fence near its surface. The field components created by linear charge densities $\tau_{\mathrm{A}}, \tau_{\mathrm{B}}, \tau_{\mathrm{C}}$ and its images $\tau_{\mathrm{A}}{ }^{*}, \tau_{\mathrm{B}}{ }^{*}, \tau_{\mathrm{C}}{ }^{*}$ are summarized. The charge density $\tau_{\mathrm{TA}}$ has opposite sign than $\tau_{\mathrm{A}}, \tau_{\mathrm{B}}$ or $\tau_{\mathrm{C}}$ but it is situated contrariwise in respect to the point of $\mathrm{M}$ therefore field direction created by $\tau_{\mathrm{TA}}$ will be coincided with field created by $\tau_{\mathrm{A}}, \tau_{\mathrm{B}}$ or $\tau_{\mathrm{C}}$ direction. The charge density $\tau_{\mathrm{TA}}{ }^{*}$ has the opposite sign than $\tau_{\mathrm{TA}}$. Because it is situated in the same direction as the $\tau_{\mathrm{TA}}$ the field direction will be contrary. So the second member of (21) is negative.

TABLE I. RESULTS OF ANALYTICAL CALCULATION AND MODELLING IN THE POINTS OF THE FENCE PLANE WITH THE HEIGHT $H=1.8 \mathrm{M}$ FOR DIFFERENT FENCE RADIUS.

\begin{tabular}{|c|c|c|c|c|c|c|}
\hline & \multicolumn{2}{|c|}{$\begin{array}{c}\text { E kV/m under } \\
\text { A phase }\end{array}$} & & \multicolumn{2}{|c|}{$\begin{array}{c}\text { E kV/m under } \\
\text { B phase }\end{array}$} & \\
\hline & Analyt. & Model. & $4, \%$ & Analyt. & Model. & $4, \%$ \\
\hline $\begin{array}{c}\mathrm{r}_{\mathrm{T}}=0,01 \\
\mathrm{~m}\end{array}$ & 11,40 & 10,26 & 10,10 & 6,64 & 6,47 & 2,6 \\
\hline $\begin{array}{c}\mathrm{rT}_{\mathrm{T}}=0,02 \\
\mathrm{~m}\end{array}$ & 12,46 & 12,38 & 0,68 & 7,28 & 7,63 & 4,85 \\
\hline $\begin{array}{c}\mathrm{r}_{\mathrm{T}}=0,05 \\
\mathrm{~m}\end{array}$ & 14,40 & 14,35 & 0,33 & 8,82 & 8,47 & 4,0 \\
\hline
\end{tabular}

For electric field strength calculation in the point $\mathrm{Q}$ under phase $\mathrm{B}$ wire we supposed that distance at fence to observation point is equal to $b$, too. The charge density in the fence under phase wire $\mathrm{B}$ is $\tau_{\mathrm{TB}}$ and its image is $\tau_{\mathrm{TB}}{ }^{*}$.
Reasoning analogically as in the case of point $M$ we obtained following expression of electric field strength $E_{\mathrm{Q}}$ in the point $\mathrm{Q}$

$$
\begin{gathered}
E_{\mathrm{Q}}=\frac{1}{K_{0}} \times\left[\frac{\tau_{\mathrm{BT}}}{b}-\frac{\tau_{\mathrm{BT}}}{2 h+b}+\frac{\tau_{\mathrm{A}}}{d_{\mathrm{BT}}-b}+\frac{\tau_{\mathrm{A}}}{d_{\mathrm{BT}}^{*}+b}+\right. \\
\left.+\frac{\tau_{\mathrm{B}}}{(H-h)-b}+\frac{\tau_{\mathrm{B}}}{H+h+b}+\frac{\tau_{\mathrm{C}}}{d_{\mathrm{BT}}-b}+\frac{\tau_{\mathrm{C}}}{d_{\mathrm{BT}}^{*}+b}\right] .
\end{gathered}
$$

The electric field several values for different diameters of upper part of the fence in the points $\mathrm{M}$ and $\mathrm{Q}$ were calculated. Some analytical results are presented in the Table I together with modelling results.

\section{Results OF Modelling}

Modelling was performed by finite elements method using program package COMSOL Multiphysics 4.4 in 3D space. Mesh with tetrahedral elements was used. The minimum distance between the nodes was chosen equal to $1 \mathrm{~mm}$. The height of fence was chosen equal to $h=1,6 \mathrm{~m}$. We supposed that line wires are cylinders with radius equal to $r_{\mathrm{F}}=0,02 \mathrm{~m}$. The electric field strength was calculated for three different radii $r_{\mathrm{T}}$ of upper fence part: a) $\left.r_{\mathrm{T}}=0,01 \mathrm{~m}, \mathrm{~b}\right) r_{\mathrm{T}}=0,02 \mathrm{~m}$ and c) $r_{\mathrm{T}}=0,05 \mathrm{~m}$. Some typical distances were chosen (Fig. 2). The electric field strength was calculated in the fence plane for heights $h=1,8 \mathrm{~m}$ and $h=1,7 \mathrm{~m}$ above the ground (points M2 and M1 in Fig. 2). For the height $h=$ $1,6 \mathrm{~m}$ the electric field strength was calculated in the plane parallel to the fence at the distance from the fence equal to $\Delta x=0,05 \mathrm{~m}$ (point M0 in Fig. 2).

The electric field strength was calculated in the plane parallel to the fence at the points situated in the distance $\Delta x=0,2 \mathrm{~m}$ in the heights $h=1,8 \mathrm{~m}, h=1,7 \mathrm{~m}$ and $h=$ $1,6 \mathrm{~m}$, too (points N2, N1 and N0 in Fig. 2). The results of modelling are presented for radius $r_{\mathrm{T}}=0,01 \mathrm{~m}$ in Fig. 6 , for radius $r_{\mathrm{T}}=0,02 \mathrm{~m}$ in Fig. 7 and for radius $r_{\mathrm{T}}=0,05 \mathrm{~m}$ in Fig. 8. It is clear from the presented results that the electric field strength increases with increasing of the radius of upper part of fence. The surface with induced charge density is approached to the points under calculation in this case. For any fence radius the field strength is maximum under the $\mathrm{A}$ and $\mathrm{C}$ phases. There are the areas near the fence for any fence radius in which the effective value of electric field strength is more than $10 \mathrm{kV} / \mathrm{m}$

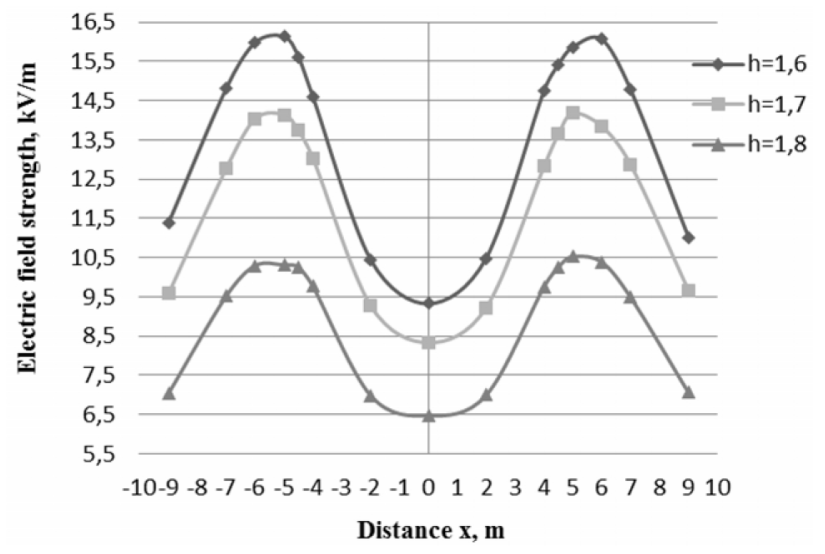

a) 


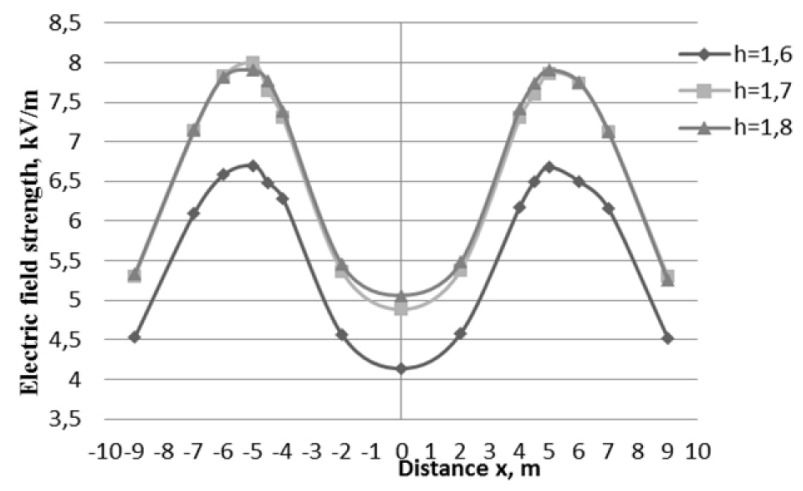

b)

Fig. 6. Electric field strength, when radius of upper fence part is $r_{\mathrm{T}}=$ $0,01 \mathrm{~m}$ : (a) for $h=1,7$ and $1,8 \mathrm{~m}$; (b) for $\Delta x=0,2 \mathrm{~m}$, for $h=1,6 \mathrm{~m}-1,8$ $\mathrm{m}$, and in the point $h=1,6, \Delta x=0,1 \mathrm{~m}$.

It is not allowable to work in the environment with such electric field strength according to European Directive 2013/35/ES. Therefore, the area near the metallic fence of open switch gear is dangerous for human.

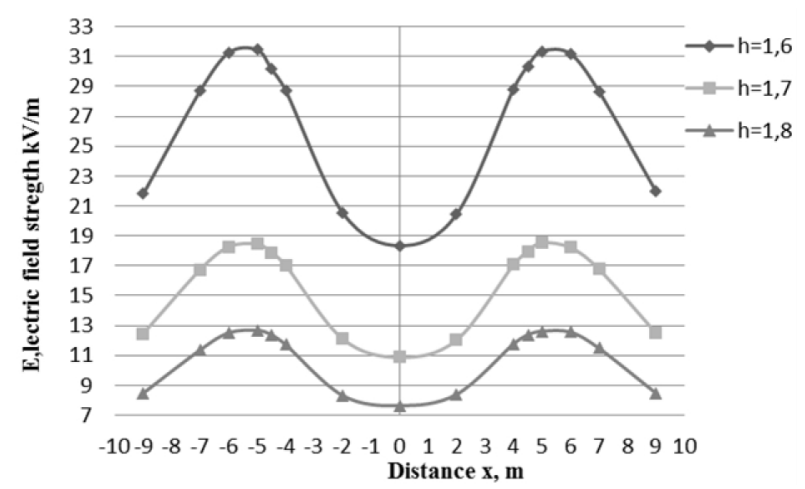

a)

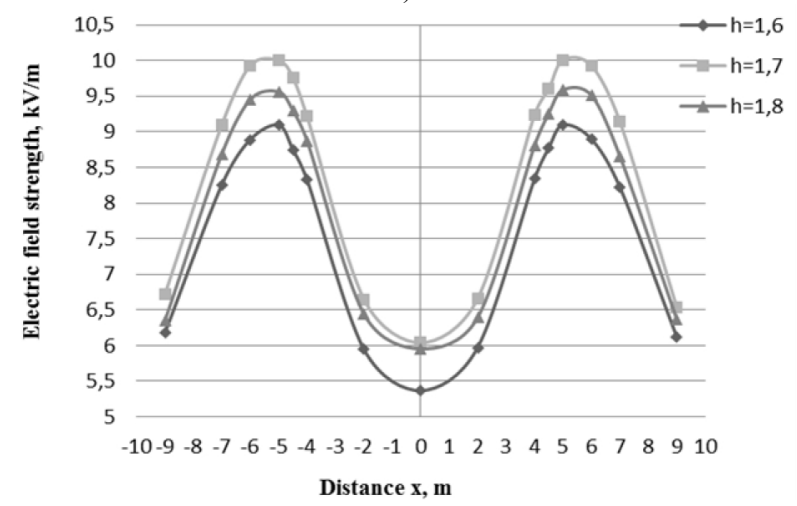

b)

Fig. 7. Electric field strength, when radius of upper fence part is $r_{\mathrm{T}}=$ $0,02 \mathrm{~m}$ : (a) for $h=1,7$ and $1,8 \mathrm{~m}$, (b) in the plane $\Delta x=0,2 \mathrm{~m}$, for $h=1,6 \mathrm{~m}$ $-1,8 \mathrm{~m}$ and in the point $h=1,6, \Delta x=0,1 \mathrm{~m}$.

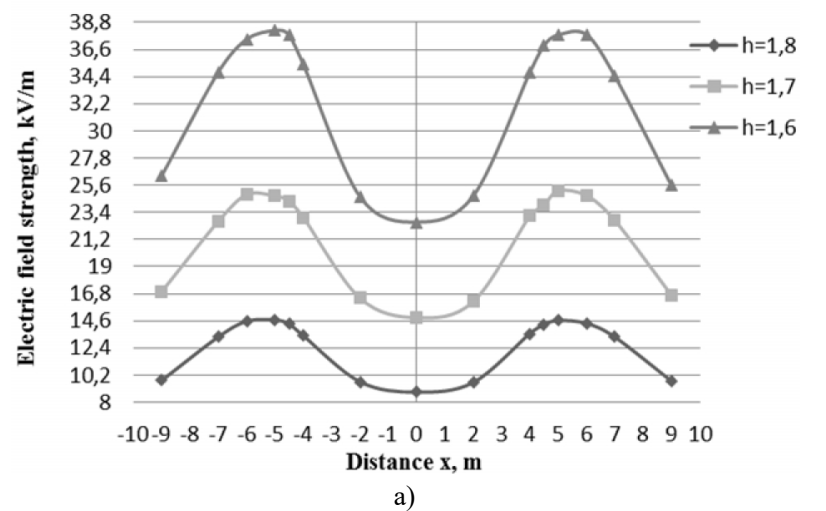

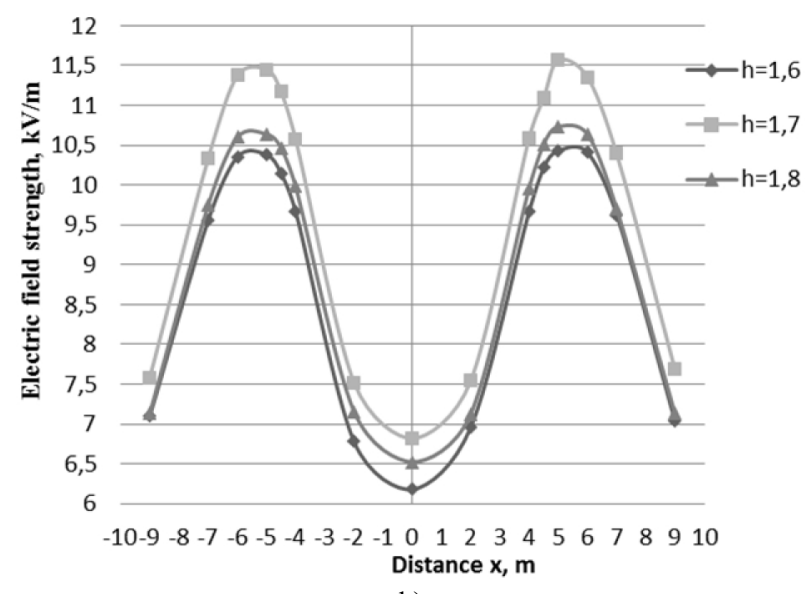

b)

Fig. 8. Electric field strength, when radius of upper fence part is $r_{T}=$ $0,05 \mathrm{~m}$ : (a) in the fence plane for $h=1,7$ and $1,8 \mathrm{~m}$; (b) in the plane $\Delta x=$ $0,2 \mathrm{~m}$, for $\mathrm{h}=1,6 \mathrm{~m}-1,8 \mathrm{~m}$ and in the point $h=1,6, \Delta x=0,1 \mathrm{~m}$.

The electric field strength was calculated analytically using the expressions (21) and (22) in the points of the fence plane with the height $h=1,8 \mathrm{~m}$ under the A phase and B phase wires for different radii of upper fence part. The results of calculation are presented in the Table I together with modelling results in the same points.

It is clear from the presented results that maximal difference (about $10 \%$ ) was obtained in the case of fence radius $r_{\mathrm{T}}=0,01 \mathrm{~m}$. In other cases, the difference does not exceed $5 \%$. Therefore, the analytical calculation of electric field strength near the metallic fence can be used for possible dangerous zones evaluation.

\section{CONCLUSIONS}

Calculation technique of the electric field strength near the metallic fence situated under high voltage line is proposed. The electric field values in some points near the fence are calculated for three different radii from upper fence part. The obtained results were verified by modelling using program package COMSOL Multiphysics 4.4. The maximal difference between the analytical and modelling results does not exceeded $10 \%$. Therefore, the presented analytical technique can be used for investigation of dangerous places near metallic fences of outdoor switchgears.

The research showed that there are some places near the metallic fence where the electric field strength exceeds the values set by European Union Directive 2013/35/ES.

The proposed analytical method can be applied for identification of dangerous zones bounds.

\section{REFERENCES}

[1] Directive 2013/35/EU of the European Parliament and the Council of 26 June 2013 on the minimum health and safety requirements regarding the exposure of workers to the risks arising from physical agents (electromagnetic fields). Official Journal of the European Union, 29/09/2004.

[2] Lithuanian Hygiene's Normative HN 104:2011 "Human protection against electromagnetic fields caused by overhead power lines", 2011, pp. 1-69.

[3] R. Deltuva, J. A. Virbalis, "Investigation of electric field in the outdoor switch-gear", Przeglad Elektrotechniczny, vol. 88, no. 7b, pp. 205-207, 2012.

[4] J. R. Stewart, L. J. Oppel, R. J. Richeda, "Corona and field effects experience on an operating utility six-phase transmission line", IEEE 
Trans. Power Delivery, vol. 13, no. 4, pp. 1363-1369, 1998 [Online]. Available: http://dx.doi.org/10.1109/61.714509

[5] A. Semlyen, D. Shirmohammadi, "Calculation of induction and magnetic field effects of three pase overhead lines above homogeneous earth", IEEE Trans. Power Apparatus and Systems, vol. 101, no. 8, pp. 2747-2754, 1982. [Online]. Available: http://dx.doi.org/10.1109/TPAS.1982.317646

[6] C. P. Nicolaou, A. P. Papadakis, P. A. Razis, G. A. Kyriacou, J. N. Sahalos, "Simplistic numerical methodology for magnetic field prediction in open air type substations", Electric Power Systems Research, vol. 81, no. 12, pp. 2120-2126, 2011. [Online]. Available: http://dx.doi.org/10.1016/j.epsr.2011.08.003

[7] Ch. P. Nicolaou, A. P. Papadakis, P. A. Razis, G. A. Kyriacou, J. N Sahalos, "Measurements and predictions of electric and magnetic fields from power lines", Electric Power Systems Research, vol. 81 no. 5, 2011, pp. 1107-1116. [Online] Available: http://dx.doi.org/ 10.1016/j.epsr.2010.12.014

[8] Y. Yang, J. Lu, Y. Lei, "A calculation method for the electric field under double-circuit HVDC transmission lines", IEEE Trans. Power Delivery, vol. 23, no. 4, pp. 1736-1742, 2008. [Online]. Available: http://dx.doi.org/10.1109/TPWRD.2008.923051

[9] A. E. Tzinevrakis, D. K. Tsanakas, E. I. Mimos, "Analysis of the electric field produced by power lines using double complex numbers", The International Journal for Computation and Mathematics in Electrical and Electronic Engineering, vol. 32 no. 1, pp. 313-336, 2012. [Online]. Available: http://dx.doi.org/10.1108/ 03321641311293911

[10] K. Dezelak, F. Jakl, G. Stumberger, "Arrangements of overhead power line phase conductors obtained by Differential Evolution", Electric Power Systems Research, vol. 81, no. 12, pp. 2164-2170, 2011. [Online] Available: http://dx.doi.org/10.1016/j.epsr. 2011.07.015

[11] A. S. Safigianni, Ch. G. Tsompanidou, "Measurements of electric and magnetic fields due to the operation of indoor power distribution substations", IEEE Trans. Power Delivery, vol. 20, no. 3, pp. 1800 1805, 2005. [Online]. Available: http://dx.doi.org/10.1109/TPWRD. 2005.848659
[12] R. S. Alipio, M. A. O. Schroeder, M. M. Afonso, T. A. S. Oliveira, S. C. Assis, "Electric fields of grounding electrodes with frequency dependent soil parameters", Electric Power Systems Research, vol. 83, no. 1, pp. 220-226, 2012. [Online]. Available: http://dx.doi.org/10.1016/j.epsr.2011.11.011

[13] M. A. O. Schroeder, M. M. Afonso, T. A. S. Oliveira, S. C. Assis, "Computer analysis of electromagnetic transients in grounding systems considering variation of soil parameters with frequency", Journal of Electromagnetic Analysis and Applications, vol. 4, no. 12 pp. 475-480, 2012. [Online]. Available: http://dx.doi.org/10.4236/ jemaa.2012.412066

[14] M. Trlep, A. Hamler, M. Jesenik, B. Stumberger, "Electric field distribution under transmission lines dependent on ground surface", IEEE Trans. Magnetics, vol. 45, no. 3, pp. 1748-1751, 2009. [Online]. Available: http://dx.doi.org/10.1109/TMAG.2009.2012806

[15] P. Taheri, B. Kordi, A. M. Gole, "Parametric study of transient electromagnetic fields due to overhead transmission lines and buried cables in the vicinity of lossy ground", IEEE Trans. Power Delivery, vol. 26, no. 4, pp. 2287-2298, 2011. [Online]. Available: http://dx.doi.org/10.1109/TPWRD.2011.2158592

[16] M. Havas, "Intensity of electric and magnetic fields from power lines within the business district of 60 Ontario communities", The Science of the Total Environment, vol. 298, no. 1, pp. 183-206, 2002. [Online]. Available: http://dx.doi.org/10.1016/S0048-9697(02)00198 $-5$

[17] L. H. Hoang, R. Scorretti, N. Burais, D. Voyer, "Numerical dosimetry of induced phenomena in the human body by a three - phase power line", IEEE Trans. Magnetics, vol. 45, no. 3, pp. 1666-1669, 2009. [Online]. Available: http://dx.doi.org/10.1109/TMAG.2009.2012771

[18] D. Djalel, M. Mourad, "Study of the influence high - voltage power lines on environment and human health (case study: The electromagnetic pollution in Tebessa city, Algeria)", Journal of Electrical and Electronic Engineering, vol. 2, no. 1, pp. 1-8, 2014. [Online]. Available: http://dx.doi.org/10.11648/j.jeee.20140201.11

[19] H. Shimada, T. Furukawa, M. Ohchi, "Electric field analysis for a static induction type of voltage sensor in three-phase power distribution systems", IEEE Proc. Generation, Transmission and Distribution, 1998, vol. 145, no. 4, pp. 437-443. [Online]. Available: http://dx.doi.org/10.1049/ip-gtd:19981957 